\title{
ARITMÔMETROS NO BRASIL NOS SÉCULOS XIX E XX
}

Circe Mary Silva da Silva

Universidade Federal de Pelotas

cmdynnikov@gmail.com

\section{RESUMO}

O presente texto discute sobre a circulação de ideias e artefatos pedagógicos entre diferentes países num processo de transferência cultural. Esta análise histórica utiliza a pesquisa documental com vistas à discutir sobre um material didático destinado ao ensino da aritmética - denominado contador- descrito no livro Arithmetica Elementar de Georg August Büchler, em 1919. Concluímos que este autor valeu-se de um livro didático para dialogar e justificar a importância de tal ferramenta no ensino do sistema decimal. Além disso, a formação de Büchler em escola normal germânica oportunizou conhecimentos de diversos materiais didáticos e permitiu uma apropriação deste conforme divulgado no livro didático Arithmetica Elementar.

Palavras-Chave: Contador. Aritmética. Transferências culturais

\section{ARITHMOMETERS IN BRAZIL IN THE 19TH AND 20TH CENTURIES}

\begin{abstract}
This paper discusses the circulation of ideas and pedagogical manipulatives between different countries in the process of cultural transference. This historical analysis uses the documentary research with a view to discussing an educational material destined to the teaching of arithmetic called - contador - described in the book Arithmetica Elementar of Georg August Büchler, in 1919. We conclude that this author used a textbook to dialogue and justify the importance of such a tool in teaching the decimal system. In addition, Büchler's training in a German Normal school allowed him to learn about various educational materials and allowed an appropriation of this material as published in the textbook Arithmetica Elementar.
\end{abstract}

Keywords: Contador. Arithmetic. Cultural Transfer

\section{LOS ARITMÓMETROS EN EL BRASIL DE LOS SIGLOS XIX Y XX}

\section{RESUMEN}

El presente texto discute sobre la circulación de ideas y artefactos pedagógicos entre distintos países en un proceso de transferencias culturales. Este análisis histórico utiliza la investigación documental con el fin de discutir acerca de un material didáctico destinado a la enseñanza de la aritmética - Contador - descrito en el libro de Georg August Büchler, de 1919. Concluimos que este autor se valió de un libro didáctico para dialogar y justificar la importancia de tal herramienta en la enseñanza del sistema decimal. Además, la formación de Büchler en escuela normal

Rev. Iberoam. Patrim. Histórico-Educativo, Campinas (SP), v. 05, p. 1-23, e019020, 2019. 


\section{$(\mathrm{cc})$ EY}

germánica le ofreció conocimientos de diversos materiales didácticos y le permitió una apropiación de todo eso conforme lo divulgado en el libro didáctico Aritmética Elementar.

Palabras-clave: Contador. Aritmética. Transferencias Culturales.

\section{LES ARITHMOMETRES AU BRESIL DU XIXE ET XXE SIECLES}

\section{RÉSUMÉ}

Le texte en question discute la circulation d'idées et les artefacts pédagogiques dans de différents pays, par un procès de transfert culturel. Cette analyse historique utilise la recherche documentaire dans le but de discuter un matériel didactique destiné à l'enseignement de l'arithmétique Contador - décrit dans le livre Arithmetica Elementar de Georg August Büchler, publié en 1919. Nous conclûmes que cet auteur s'est aidé d'un livre didactique pour dialoguer et justifier l'importance de tel outil dans l'enseignement du système décimal. En outre, la formation de Büchler en école normale germanique lui a offert des connaissances de divers matériels didactiques et lui a permis une appropriation de ceux-ci selon ce qui fut publié dans le livre didactique Arithmetica Elementar.

Mots-clés: Boulier-compteur. Arithmétique. Transfert Culturel.

\section{CONTEXTO}

A história não cansa de nos ensinar que o passado pode ser acessado de várias maneiras. Ao tomarmos um livro didático como fonte, estamos dando a este um novo estatuto, entendido como um manancial passível de releituras. Os livros didáticos são meios, entre outros, de divulgar novas ideias e metodologias de ensino. Espagne (1999) incluiu autores, imigrantes e livros como vetores de transferência cultural.

Nesse sentido, a questão investigativa busca identificar materiais didáticos para o ensino de aritmética, em especial os aritmômetros, que circularam no Brasil e identificar agentes de transferências de tais dispositivos pedagógicos.

No presente texto, discuto sobre um material didático descrito em livro didático publicado no Brasil, em 1919, e que remete a um "retorno" ao século XIX no sentido de repensar sobre a o papel desempenhado pelos pedagogos como Marie Pape-Carpentier, que ao defenderem um ensino voltado para a prática, criaram um "arsenal" de materiais didáticos, que circularam entre países numa proliferação de ideias a nível transnacional.

O uso de materiais didáticos não é novidade. Desde o século XIX, pedagogos e pedagogas os discutiam e utilizavam no ensino da matemática, conforme exemplificaremos no presente texto. 


\section{$(\mathrm{cc})$ EY}

Buisson (1887) chamou de boulier-compteur ou ábaco, instrumentos utilizados em salas de classes elementares básicas para introduzir crianças pequenas à prática de cálculo. Considera-se os ábacos e outros materiais similares como o contador aritmômetros, por exemplo, o contador. A ideia de crianças contando objetos materiais antes de compreender os números abstratos, segundo ele, é natural demais para não ser tão antiga quanto a civilização. Marie Pape-Carpantier (18151878), pedagoga francesa, defendeu um ensino prático nas escolas maternais. Em 1848, publicou a obra L'enseignement pratique dans les écoles maternelles ou premières leçons à donner aux petits enfants. Nesta, apresentou um artefato chamado boulier numérateur (Figura 1), conforme descrito por Regner (2003).

Figura 1- Modelo do ábaco de Marie Pape-Carpantier, 1848.

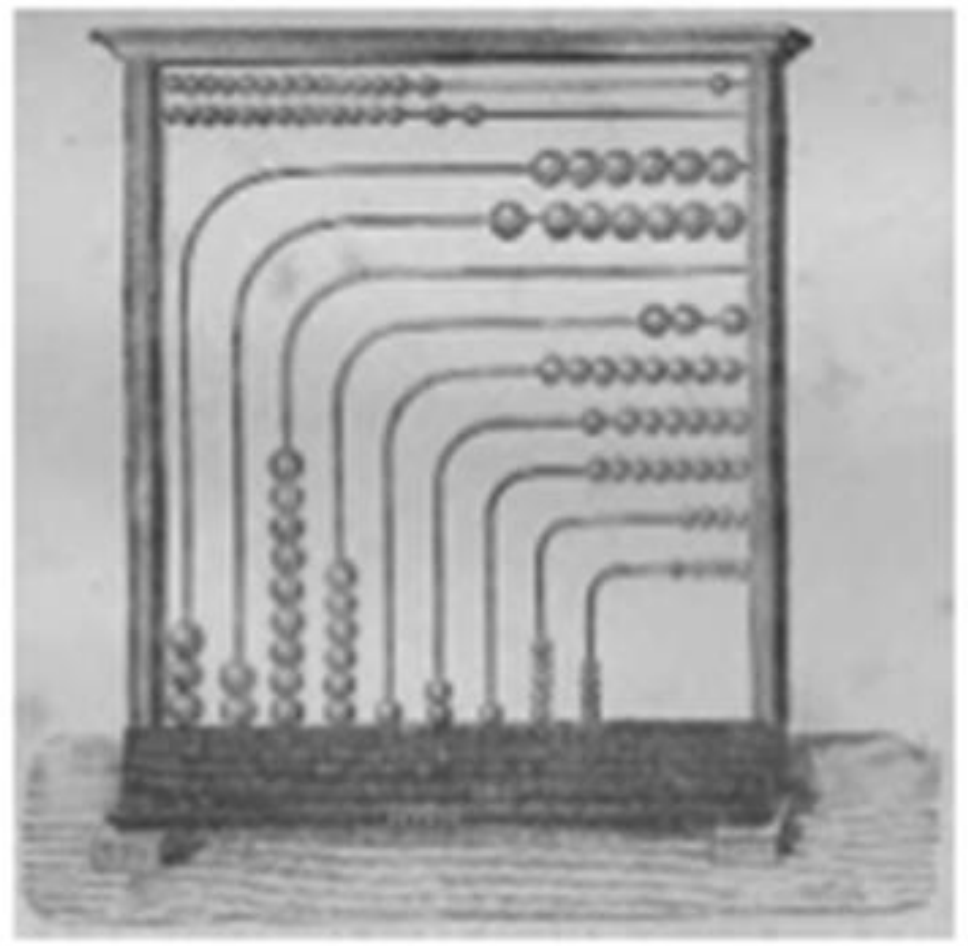

Fonte: Regner, 2003, p. 9.

Em 1882, no relatório do Conselho Interino do Governo da Bahia aparece referência aos materiais didáticos usados pela professora Adelaide Francisca de Souza Rebello: material para o ensino da educação dos sentidos de Marie Pape-Carpentier, material para a escola de Froebel; numeradores de Cordier e Chabenat; Arithmometro de Petry, etc. (RELATÓRIO, 1882, p. 76-77).

No Brasil, os denominados "contadores mecânicos", também conhecidos como ábacos, aparecem nos jornais desde o século XIX, principalmente no rol de materiais didáticos adquiridos

Rev. Iberoam. Patrim. Histórico-Educativo, Campinas (SP), v. 05, p. 1-23, e019020, 2019. 


\section{$(\mathrm{cc}) \mathrm{BY}$}

para as escolas primárias. Na Exposição Pedagógica de 1883, no Rio de Janeiro, os contadores mecânicos e aritmômetros ${ }^{1}$ encontravam-se entre os objetos a concorrem na avaliação dos juízes (EXPOSIÇÃO, 1883, p. 3).

Participaram daquela exposição representantes dos seguintes países: Bélgica, Alemanha, Espanha, França, Inglaterra, Suécia, Itália, Estados Unidos e naturalmente o Brasil, integrando o grupo 7, que abrangia objetos e livros elementares de cálculo (EXPOSIÇÃO, 1883, p. 2). Entre as discussões pedagógicas que ocorreram à época, estava o método intuitivo considerado “[...] o meio mais apropriado para tornar concreto o que é abstrato, e para vencer a maior parte das dificuldades que apresenta o ensino elementar" (EXPOSIÇÃO, 1883, p. 2). A comissão avaliadora de tal grupo chamava a atenção que quase todas as nações haviam inventado numerosos contadores, numeradores, arithmômetros e aparelhos similares, que estavam presentes na Exposição. No dicionário de Buisson há referência a vários desses aparelhos entre eles, o aritmômetro de Martinot, que ele descreveu:

[...] as unidades simples representadas por mil pequenos cubos com um centímetro de aresta; as dezenas por fileiras alinhadas de dez desses pequenos cubos; as centenas por dez dessas fileiras, formando uma placa com cem cubos pequenos. O milhar é representado por um decímetro cúbico. É fácil com esse engenhoso aparato executar visualmente cálculos complicados [...]. (BUISSON, 1887, p. 118).

Conforme Pais (2014) o aritmômetro de Arens, desenvolvido pelo irmão lassalista Marianus e aperfeiçoado ao longo de vários anos de experiência pelos Irmãos Lassalistas visava a aprendizagem do sistema de numeração decimal.

Irmão Marianus esteve presente na Exposição Pedagógica do Rio de Janeiro, em 1883, acompanhando a comitiva belga. Dom Pedro II assistiu à conferência sobre o funcionamento do aparelho e para expressar o júbilo imperial prestou homenagem ao religioso concedendo-lhe a Comenda da Ordem de Cristo (PAIS, 2014, s.p.).

A fim de orientar os professores no uso dos arithmômetros, foi editado um livro intitulado Guia pedagógico do Calculo mental e uso do contador mechanico ou arithmometro no ensino

\footnotetext{
${ }^{1}$ Buisson identificou um aritmômetro [arithmomètre] como uma máquina de calcular (1887, v. 2, p. 118). Afirmava que, na Bélgica, métodos têm sido usados para construir aparelhos para o estudo completo do sistema numérico e do sistema métrico.
}

Rev. Iberoam. Patrim. Histórico-Educativo, Campinas (SP), v. 05, p. 1-23, e019020, 2019. 


\section{$(\mathrm{cc}) \mathbf{E Y}$}

elementar da aritmética, traduzido e adaptado para as escolas por Brasilicus ${ }^{2}$ (AVISO, 1883, p. 2), que evidencia a importância atribuída à época a tais materiais didáticos. Para este autor, a essência de um arithmometro:

[...] consiste em um quadro com dez varetas horisontaes de arame ou ferro (de 5 millimetros de diametro), em cada uma das quaes são enfiadas dez bolas ou espheras de madeiras, ou qualquer outra matéria (de 5 a 8 millimetros de diâmetro), de sorte que possam folgadamente correr de uma a outra extremidade. - As varetas devem ser mais compridas do que o espaço occupado pelas espheras, para que se possam executar varias combinações em cada uma das mesmas varetas, e além disso contenham mais a taboinha móvel estreita $\mathrm{A}, \mathrm{B}$, ou $\mathrm{C}$, que lhe deve ser adaptada conforme for necessario ao ensino (BRAZILICUS apud TEIXEIRA, 2014, p. 619).

No período de 1883 a 1901, lê-se nos jornais periódicos do Rio de Janeiro muitas notícias sobre aquisição de arithmômetros para as escolas públicas e propagandas sobre o Guia Pedagógico acima referido.

Na mesma exposição Pedagógica, Abílio César de Borges, professor brasileiro e diretor de colégio, apresentou seu aparelho múltiplo que também foi premiado. Segundo Pais (2014), tal aparelho tinha os seguintes elementos: ábaco; fraciômetro ${ }^{3}$, contador vertico-horizontal; aparelho cromático, sólidos geométricos entre outros.

Posteriormente, neste texto, mostro que o aritmômetro de Martinot, descrito por Buisson, já era conhecido nos reinos alemães vários anos antes de tal referência.

Luiz Augusto Reis viajou como emissário oficial do governo brasileiro, em dezembro de 1890, a Portugal, Espanha, França e Bélgica para conhecer o ensino público primário daqueles países. Ele constatou que em Portugal e Bélgica os "contadores mecânicos", "bolários contadores" ou "contadores com bolas coloridas" eram utilizados nas escolas primárias juntamente com outros materiais didáticos visando facilitar o processo de um ensino intuitivo (REIS, 1892, p. 221, p. 382, p. 552).

O artigo intitulado Uso do Contador Mechanico de Isabel de Castro apareceu no primeiro número da Revista Eschola Publica (1896) procurando estimular o professor a fazer uso do contador mecânico no ensino da contagem, na escola primária. Ele aparece na Figura 2.

\footnotetext{
${ }^{2}$ Conforme Teixeira ( 2014) o tradutor foi José Carlos de Alambary Luz, que usou esse pseudonimo.

${ }^{3}$ Segundo Pais, o fraciômetro era a parte do instrumento, criado por Borges, que ele a considerava como inovadora.

Rev. Iberoam. Patrim. Histórico-Educativo, Campinas (SP), v. 05, p. 1-23, e019020, 2019. 
Figura 2 - Contador mecânico.

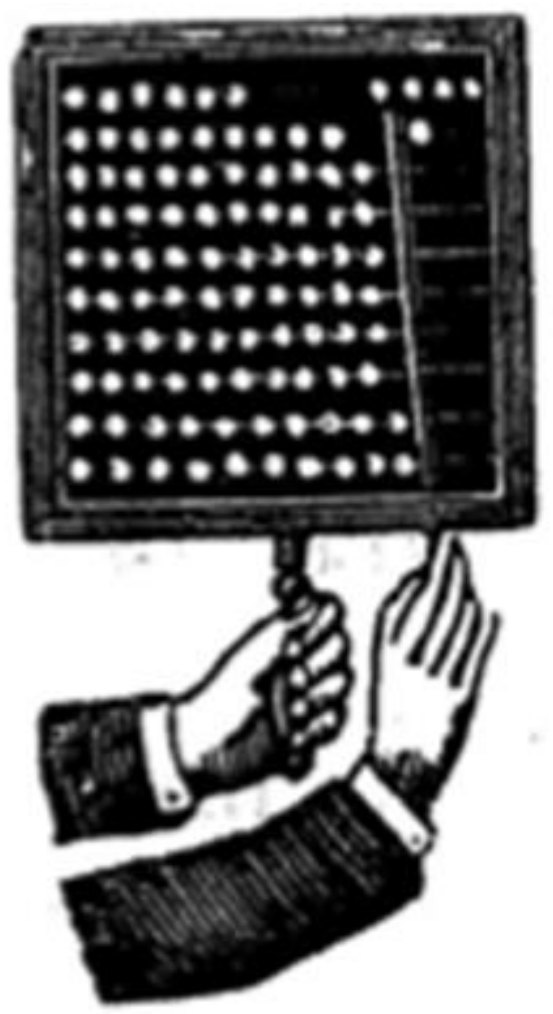

Fonte: Castro, mar. 1896, p. 41.

Artefatos, ferramentas, objetos comuns de manusear como pauzinhos, contas, botões, feijões entre outros de uso comum em sala de aula, como os contadores, pertencem ao que Unger (1888) denominou de materiais visuais, utilizados como representações no ensino da matemática desde o final do século XVIII.

[...] A apropriação de uma ferramenta pelo professor não tem a função essencial de transformar sua maneira de pensar, mas de melhor realizar seu métier de transformação [...]; a apropriação de uma ferramenta pelo aluno visa essencialmente a transformação de seus modos de pensar, falar ou de fazer: ele está em situação de aprendizagem que o professor organiza precisamente pela criação de um ambiente (PLANE; SCHNEUWLY, 2000 p. 8, tradução livre da autora).

Embora os autores acima citados refiram-se especialmente a ferramentas para o ensino da língua francesa, eles trazem à discussão o relevante tema dos materiais didáticos, por eles denominados de ferramentas, assim como o seu papel no ensino. Entretanto, o mais importante na 


\section{$(\mathrm{cc}) \mathbf{E Y}$}

discussão desses autores diz respeito à fundamentação teórica apresentada em três campos: o antropológico, psicológico e o da própria ferramenta. Argumentam que do ponto de vista do campo antropológico justifica-se pelo fato de que é próprio da espécie humana o trabalho com ferramentas. Para o campo psicológico, afirmam que as transformações dos processos psíquicos necessitam de ferramentas mentais. No terceiro campo trazem a dupla função de ferramenta como artefato e como esquema de utilização.

No regulamento da instrução pública primária de Sergipe de 1890, consta no artigo 24, os materiais para cada escola: um arithmometro de Arens e contadores mecânicos, coleção de padrões de pesos e medidas, entre outros (Decreto 14 de março de 1890). No século seguinte, em jornais, mensagens de governadores associavam a aquisição de material pedagógico com modernidade. Não apenas o centro do país, preocupava-se com um ensino moderno, um exemplo disso é a mensagem de Manoel Correa Dantas, governador de Sergipe, que ao adquirir 73 contadores mecânicos traz como justificativa o seguinte argumento:

Para que verdadeiramente seja ministrado o ensino objetivo, que caracteriza a educação moderna, pois é pela observação que melhor se adquire o conhecimento certo das coisas, tenho procurado aparelhar todas as escolas do material pedagógico preciso (DANTAS, 1929, p. 2).

Uma rápida incursão à história da educação no Brasil, no século XX, no Brasil, mostra que discussões sobre materiais didáticos ocorriam principalmente em manuais de didática geral e especial. Por exemplo, Theobaldo Miranda $\operatorname{Santos}^{4}$ (1955) denominava de materiais didáticos:

[...] todos os objetos que auxiliam o professor a exercer sua função educativa. Compreende não só objetos artificiais, como gravuras, fotografias, instrumento, aparelhos, utensílios, livros, papel, tinta, giz, pena, etc., como também objetos naturais, como plantas, animais e minerais (SANTOS, 1955, p. 246).

Em 1960, no livro sobre Noções de didática especial, referindo-se a matemática ele diz ser importante a utilização de material que concretize os números e operações:

Esse material pode ser simples e natural, como os dedos da mão, feijão, palitos, pedrinhas, etc., ou artificial como cartazes, gravuras, desenhos recortados, fichas, bolinhas de vidro ou de massa, etc. Há ainda os aparelhos de aritmética como o ábaco ou contador, os tabuleiros das unidades e frações, as caixas de cálculo de Tillich, o tabuleiro de Gersbach, a coleção de pesos e medidas para o ensino do

\footnotetext{
${ }^{4}$ O livro de Theobaldo Miranda Santos, mesmo não pertencendo ao período investigado, foi referenciado porque
} menciona os aritmômetros alemães.

Rev. Iberoam. Patrim. Histórico-Educativo, Campinas (SP), v. 05, p. 1-23, e019020, 2019. 
sistema métrico, o relógio escolar, os jogos aritméticos, etc. (SANTOS, 1960, p. 153).

Na citação acima aparecem as caixas de Tillich, tema que será explicitado ainda neste texto. Mas além da referência a materiais didáticos nos livros de didática, constatei, no livro intitulado Aritmética Prática de Georg August Büchler, sugestões de uso de um material didático específico para a introdução do sistema decimal - o contador. Uma análise detalhada de tal aparato é objetivo principal, no presente texto.

\section{TRANSFERÊNCIAS CULTURAIS - ALEMANHA E BRASIL}

O termo transferência cultural marca a preocupação de falar simultaneamente de vários espaços nacionais, de seus elementos comuns, sem justaposição das considerações sobre um e outro para confrontá-los, compará-los ou simplesmente acumulá-los (ESPAGNE, 1999, p. 1).

Fontaine (2014), ao discutir sobre as transferências culturais franco-suíças, lança uma instigante questão: "E se as nossas estruturas escolares nacionais não fossem de fato senão a realização de absorções e de apropriações recíprocas?” (FONTAINE, 2014, p. 187). A partir dessa questão, ele pretende reavaliar a circulação de conhecimentos entre países europeus. Meu propósito, a partir das provocações de Fontaine, é discutir como modalidades de práticas pedagógicas, que incluem a produção de material didático para o ensino da aritmética, ultrapassaram fronteiras e aportaram no Brasil, com transformações decorrentes deste processo.

Perseguindo numa linha de tempo, os atores e intermediários nesse processo, foco o olhar àqueles que foram os responsáveis diretos pela introdução de propostas inovadoras de práticas de ensino para as escolas primárias (primeiros anos do ensino fundamental atual). A esses atores denomino agentes culturais. Por agentes culturais entendo aqueles atores individuais que, em seu ofício de professor ou escritor, tornaram-se mediadores de saberes e permitiram a ocorrência de transferência de um saber de um contexto cultural para outro.

Cabe destacar que não apenas agentes culturais foram responsáveis por transferências culturais. A investigação de Dittrich (2013) sobre o papel das Exposições Universais, eventos transnacionais, iniciados na segunda metade do século XIX, mostra que por meio deles ocorria um “aprender com o estrangeiro" (DITTRICH, 2013, p. 216). Além disso, esses eventos permitiam um 


\section{(c) $) \mathrm{EY}$}

início de colaboração internacional. A partir de 1862 tais exposições ampliaram seu palco incluindo a educação. Nas seções escolares haviam mostras de livros, aspectos físicos das instituições de ensino, das escolas modelos, dos métodos de ensino e inclusive de modernos objetos pedagógicos, que incluíam máquinas de calcular (ábacos). Outro exemplo de transferência cultural ocorreu quando o Brasil promoveu a Exposição Pedagógica de 1883, com a participação de representantes de países estrangeiros. Os materiais didáticos relativos ao ensino da aritmética pertenciam ao grupo 7 e entre eles estavam os aritmômetros, fraciômetro ou material de Martinot, aparelho de Level, caixa de Carpantier, contadores mecânicos entre outros. Assim, concordo com Fontaine, é difícil em termos de educação, pensar que os desenvolvimentos de cada país ocorreram sem influências mútuas.

Benito (2017, p. 39) advoga sobre o papel dos sujeitos, dos atores, dos agentes que geram a cultura escolar, dizendo que estes atores: "[...] adaptam as mudanças suscitadas a partir do exterior das instituições. Isso se dá mediante processos peculiares de apropriação, aos quais têm a ver com os hábitos e as tradições [...]". Concordo com esse autor quando fala sobre a importância de valorizar a experiência, os elementos que produzem a cultura escolar, e assim realizar um retorno à consideração da ação dos sujeitos na escola.

No Brasil atuaram agentes culturais, entre os quais é possível incluir a personagem Georg August Büchler (1884-1962), estrangeiro que emigrou para o Brasil em 1905 e que permaneceu no País até a sua morte, em 1962. Que mediações realizou entre conhecimentos produzidos na Europa e Brasil para o ensino da matemática elementar? No presente artigo, concentro-me nas transferências de saberes entre dois países: Brasil e Alemanha, num agente cultural - Georg August Büchler e em materiais didáticos específicos para o ensino da aritmética: um livro escolar e $o$ contador.

\section{MATERIAIS DIDÁTICOS PARA A ARITMÉTICA NA ALEMANHA}

Principalmente a partir do início do século XX, com o aumento significativo de imigrantes germânicos para o Brasil, chegam professores para atuarem em estabelecimentos de ensino, nas regiões de imigração, alguns deles com formação nos Seminários de professores [Lehrerseminar]. Torna-se incompleta uma análise do contexto de produção e circulação de práticas escolares no Brasil sem estabelecer um paralelo com o que acontecia em outros países.

Rev. Iberoam. Patrim. Histórico-Educativo, Campinas (SP), v. 05, p. 1-23, e019020, 2019. 


\section{$(\mathrm{cc}) \mathrm{EY}$}

Na Europa, no decorrer do século XIX, principalmente a partir das ideias de Pestalozzi visando a um ensino mais intuitivo e baseado em experiências sensoriais, surgiram uma variedade de recursos didáticos de aritmética e geometria, desenvolvidos em vários países e inclusive os países de língua germânica. Não cabe, nesse artigo, discutir sobre as mútuas influências entre países de fala germânica e outros países europeus. Mas, seria ingênuo supor que a produção de material didático para o ensino da matemática não tenha se apoiado em apropriações recíprocas, conforme Fontaine (2014) e Dittrich (2013) sinalizaram.

Pais (2014, s.p.) em seu artigo sobre a História dos Aritmômetros também ressalta que: “A história dos recursos didáticos, no período focalizado, está inserida no movimento educacional de valorização do método de ensino intuitivo, cujas raízes estão associadas à pedagogia alemã do final do século XVIII".

Na obra de Unger (1888) encontra-se uma relação de materiais didáticos, que incluem autoria e data de divulgação. Não foi possível determinar a partir do texto deste autor, a frequência e os locais em que foram utilizados.

Unger reuniu trinta e três materiais visuais e os classificou em: meios visuais materiais e meios visuais gráficos. Descreveu cada um deles. Entre estes o denominado ábaco russo, que ele denominou de máquina de calcular russa [russische Rechenmaschine], na Figura3.

Figura 3 - Ábaco russo.

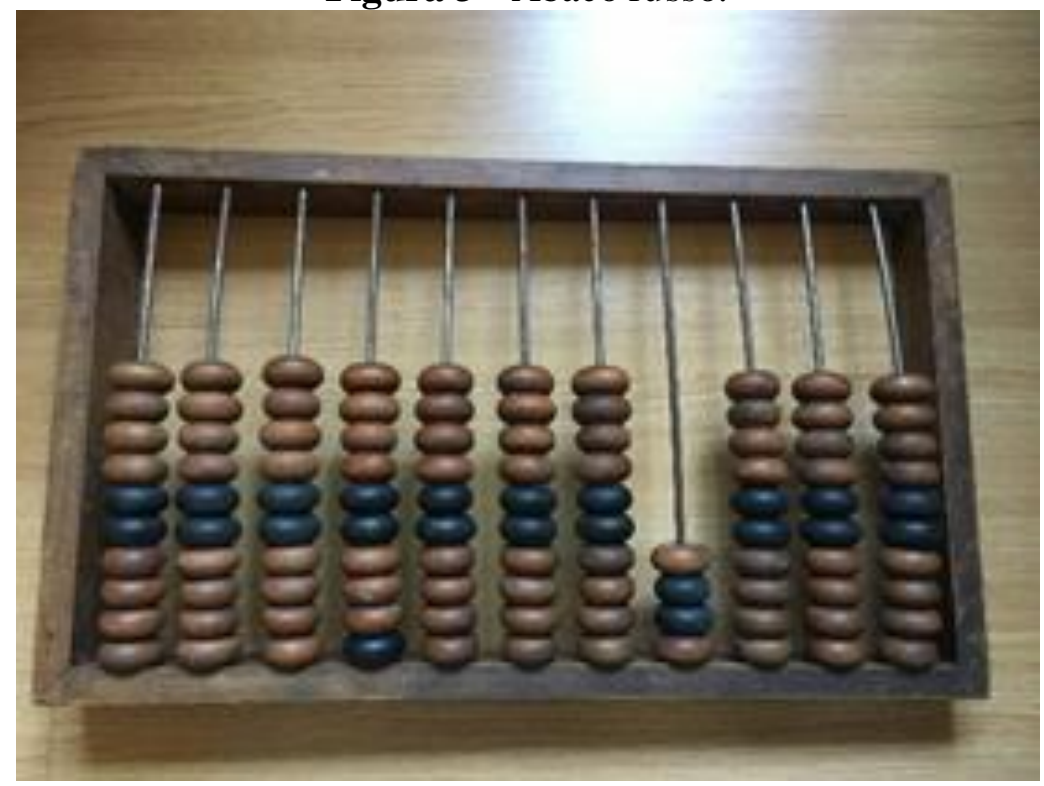

Fonte: acervo particular da autora. 


\section{$(\mathrm{cc}) \mathrm{EY}$}

Unger entendia como meio de visualização tudo aquilo que serve para compreender o número e as unidades que o compõem e que devem ser visualizadas pelos objetos ou por sinais separados. No primeiro grupo incluiu os aparatos envolvendo esferas, varinhas, cubos, botões e moedas. No segundo, os gráficos, aqueles desenhos em que são feitos por traços, pontos, quadrados e círculos. Descreveremos apenas quatros desses aparatos pertencentes ao primeiro grupo, que foram usados no século XVIII e XIX, nos países de fala germânica, porque estes são mais próximos dos aritmômetros que circularam no Brasil.

O feixe de pauzinhos de Overberg (fonte citada: Anweisung zu zweckmäss. Schulunterricht, Münster, 1793) - Foram usados pauzinhos finos (palitinhos) de um pé de comprimento para representar as unidades. Um pauzinho para representar as unidades; 10 pauzinhos (bastãozinhos) amarrados chama-se um feixe; para 100 um maço, para 1000 um pacotinho e para 10.000 um pacote. (UNGER, 1888, p. 204, tradução livre da autora).

Caixa de calcular de Tillich (1780-1807). A ideia de que as unidades de um número podem ser representados por cubos é de Ernst Tillich (que seguiu, na primeira década do século XIX, as ideias de Pestalozzi sobre visualização). De acordo com sua descrição, os prismas de madeira com tinta branca, estão circulados por linhas pretas, os cubos individuais pretos compõem um prisma para os distinguir. No uso da madeira, os alunos usam uma ardósia com uma rede quadrangular e desenham o número de cubos nos quadrados. (UNGER, 1888, p. 204, tradução livre da autora).

Os cubos de Heer - da obra de Herr (Fonte: Lehrbuch des Denkrechnens, 1836) Constitui-se de cubos iguais (10 unidades de representação), 9 torres iguais com o cubo unitário como base, mas com a altura de 9 cubos (cada torre representa o número 10) e 9 pratos quadrados, os quais tem 10 torres colocadas uma ao lado da outra, o que representa o número 100. (UNGER, 1888, p. 204, tradução livre da autora).

O aparato de Krammer - (Fonte: Prausek : Über die verwendbarsten Lehrmittel z. Ersten Unterricht im Rechnen, Olmüz, 1864) - é formado pelos cubos de Heer. Constitui-se de 5 cubos brancos e 5 cubos pretos que representam as unidades; 10 prismas (para as 10 dezenas), as quais tem o tamanho de 10 cubos colocados juntos um ao lado do outro alternando as cores; 10 pratos quadrados (para 10 centenas), que tem a altura do cubo e o comprimento do prisma e cujo desenho é semelhante a um tabuleiro de xadrez, a superfície mostra 100 células quadradas; um grande cubo com 1000 cubos de unidades e que em cada face se vê um tabuleiro de xadrez de 100 quadrados. (UNGER, 1888, p. 205, tradução livre da autora).

Rev. Iberoam. Patrim. Histórico-Educativo, Campinas (SP), v. 05, p. 1-23, e019020, 2019. 


\section{(cc) EY}

A ausência de imagens, no texto de Unger, limita a compreensão dos materiais didáticos por ele descritos. Entretanto, a caixa de Tillich (século XVIII), os cubos de Herr de 1836 e o aritmômetro de Martinot, descrito por Buisson, são muito semelhantes ao que ficou conhecido no Brasil como material dourado ou material de Montessori, no século XX.

É preciso ressaltar que nos Seminários de Formação de Professores, nos reinos alemães, no século XIX, era fortemente recomendado o uso de materiais didáticos. Lexis (1904), em sua obra sobre O Sistema Escolar no Reino Alemão [Das Unterrischtswesen im Deutschen Reich], aponta para o papel importante desempenhado pelo material didático, afirmando que nas diferentes disciplinas: "[...] os aspectos metodológicos são discutidos, sempre com a apresentação de importantes meios auxiliares, tais como figuras ilustrativas, máquinas de leitura e de aritmética, mapas, globos, aparelhos para ginástica e similares” (Lexis, 1904, p. 301).

\section{O CONTADOR NO LIVRO DE GEORG BÜCHLER EM 1919}

Georg August Büchler, imigrante alemão com formação no Seminário de Formação de Professores [Grossherzoglichen Schullehrer-Seminars], em Hessen, chegou no Brasil em 1905. Publicou em 1919 a primeira parte do livro intitulado Arithmetica Elementar, em São Paulo, pela editor Weiszflog Irmão (Silva, 2016). Büchler, numa fuga da rispidez de um tratamento muito teórico e dedutivo da aritmética, ao escolher deliberadamente o que fazia parte do universo infantil, optou em seu livro por dialogar com os alunos e o professor por meio de textos e imagens. Não poupou uma forte retórica à apresentação de saberes elementares da aritmética, entremeada de imagens com representações de cenas do cotidiano de uma criança à época. Entretanto, as edições posteriores sofreram modificações drásticas. Os textos explicativos, que orientavam o professor na utilização do livro, desapareceram e, em 1942, a $4^{\mathrm{a}}$ edição continha apenas 122 páginas, enquanto a $1^{\mathrm{a}}$ edição, 232 páginas. A introdução de um aparato denominado contador apareceu pela primeira vez quando Büchler apresentou o conceito de dezena. Embora o autor tenha usado a denominação “contador", esta palavra não deve ser confundida com a usada por Reis (1892), contadores mecânicos, pois aqueles eram um tipo de ábacos.

A construção do conceito de dezena, que na versão de 1942 apareceu apenas de maneira abreviada, mereceu na primeira edição um longo texto dialógico que inicia com o tema fósforos apoiado na imagem da Figura 4.

Rev. Iberoam. Patrim. Histórico-Educativo, Campinas (SP), v. 05, p. 1-23, e019020, 2019. 


\section{$(\infty))_{E Y}$}

Figura 4 - Pacotes de fósforos no balcão do armazém.

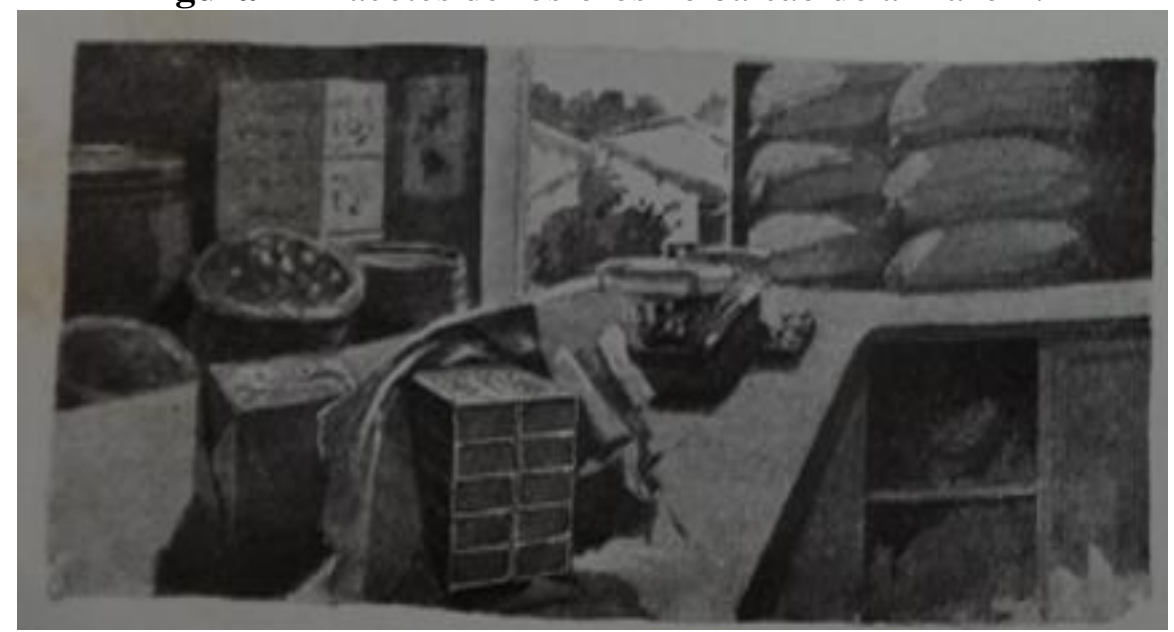

Fonte: Büchler, 1919, $1^{\mathrm{a}}$ ed., p. 110

A partir da Figura 4, ele propõe exercícios para os alunos embrulharem os pacotes de fósforos. Segue um extrato deste diálogo:

Vocês todos trouxeram de casa 10 caixas? Vou dar a cada um de vocês um papel de tamanho certo para vocês fazerem um pacote. Quantas caixas você tem diante de si? Quantos pacotes você vai fazer das 10 caixas? Aonde você põe o pacote? (lado esquerdo) Quantas caixas estão à direita? (nenhuma). De 10 caixas de fósforos fazemos um pacote e não fica nenhuma caixa do lado direito. Em lugar de um pacote de 10, a gente também diz: uma dezena. Uma dezena são $5+5$. Uma dezena de tostões são 10 tostões. Vocês viram que de 10 caixas fizemos um pacote ou uma dezena. Vamos agora formar uma dezena de pauzinhos. Quantos pauzinhos preciso colocar embaixo? Quantos em cima? [...] Olhem aqui tenho uma caixa em que há lugar para cada um dos pauzinhos. [...] Esta caixa contem 10 pauzinhos ou uma dezena. Esta caixa eu coloco no lado esquerdo da mesa. Quantos pauzinhos ficaram fora da caixa aqui a direita? (nenhum). (BÜCHLER, 1919, p. 114-115).

O texto permite entrever que o autor para introduzir o contador, apoiou-se na ideia de uma caixa de fósforos e na possibilidade de reunir essas caixas num pacote, e ainda formar novos pacotes de pacotes.

Nesta primeira edição, o autor denomina esse material didático de contador. Usando uma estratégia sútil, o autor começa a mostrar imagens de uma caixa sobre uma mesa, que só ao longo do texto merecerá uma explicação: são pauzinhos e várias caixas com diferentes tamanhos que

Rev. Iberoam. Patrim. Histórico-Educativo, Campinas (SP), v. 05, p. 1-23, e019020, 2019. 


\section{(cc) EY}

integram o aparato que ele denominará de contador. A leitura da descrição da caixa das dezenas deixa entrever que esta possuía repartições onde cabiam pauzinhos de madeira (Figura 6). A caixa que representa uma dezena contém 10 pauzinhos (Figura 5). Na caixa que representa a centena cabem 10 caixas de dezenas e na caixa maior que representa o milhar cabem 10 caixas de centenas.

Figura 5 - Representação do conceito de dezena no Contador.

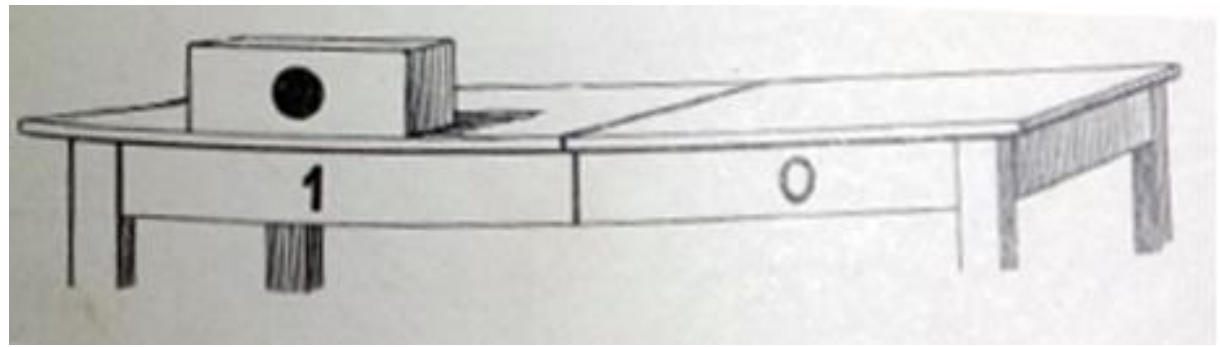

Fonte: Büchler, 1919, p. 115.

Somente na página 150, ele esclarece que esse aparato chama-se contador. Assim ele estabelece um diálogo com o aluno: "Venha contar doze no contador! Quantos pauzinhos cabem em uma caixa? Quantos coloca na outra? Conte 2, 4, 6,...Quantos ficam em baixo? Em cima?" (BÜCHLER, 1919, p. 150).

Figura 6 - Representação do número 12 no Contador

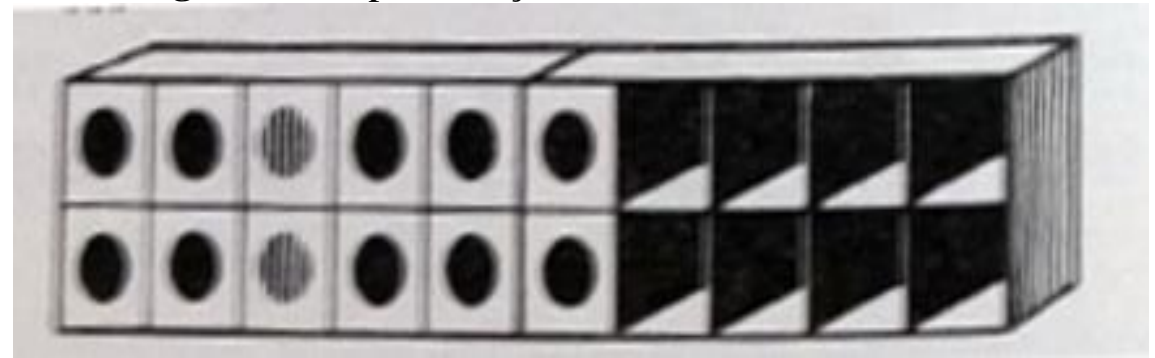

Fonte: Büchler, 1919, p. 150

As detalhadas explicações sobre o contador continuam nas páginas seguintes, como no exercício XX, e estão apoiadas numa figura:

Quantos pauzinhos você precisa para encher uma caixa? Vocês vêem aqui uma dezena à esquerda e nada á direita. Quantos pauzinhos são? (10) Escreva 10! Por que você escreve 1 á esquerda e cifra á direita? (porque 1 dezena está á esquerda e nada á direita). Olhem! Coloco á direita uma caixa vazia. Quantos pauzinhos você vê? (10) Onde estão? (á esquerda). Coloque 1 á direita! Leia (11) Diga 11 são 1 dezena mais 1. Escreva 11! Coloque mais 1 á direita! Leia! Quanto é 12? (1

Rev. Iberoam. Patrim. Histórico-Educativo, Campinas (SP), v. 05, p. 1-23, e019020, 2019. 

Coloque mais 1 á direita Leia! Quanto é 15? Escreva 15! (BÜCHLER, 1919, p. 153).

Ele prossegue com o mesmo diálogo até chegar ao número 20. Aí diz: "A caixa à direita está cheia. Podemos fechá-la com a tampa. Quantos pauzinhos contém esta caixa? Que nome damos a uma caixa de 10? (dezena) Aonde devo colocar a dezena? (no lado esquerdo da mesa). Quantas dezenas temos agora?” (p. 154). As explicações apoiadas nas imagens seguem-se acompanhadas de sugestões de atividades como: “Coloque no contador 17!, 15, 19, 16). Conte se o número está certo" (BÜCHLER, 1919, p. 154).

Num exercício dialogado o autor propõe o aumento de pauzinhos até o completamento da terceira caixa. Comenta então: “O que fazemos sempre que uma caixa está cheia? Fechamo-la e colocamo-la no lado esquerdo. [...] Venha contar os pauzinhos sem abrir as caixas!” (BÜCHLER, 1919, p. 166). Ao chegar na contagem envolvendo o número 50, novamente, o contador entrou em cena. Encontramos, na página 187, uma pista sobre o tipo de material. É solicitado que o aluno conte quantos pauzinhos estão sobre a mesa. A seguir pergunta: "De que são feitos os pauzinhos? Quem fez os pauzinhos? O que precisa o marceneiro para fazer os pauzinhos?” (BÜCHLER, 1919, p. 187).

A partir desta descrição, entende-se que o contador é formado por pauzinhos (talvez de madeira leve) e as caixas com subdivisões e tampas.

Para introduzir a centena, ele traz uma imagem (Figura 7) acompanhada do seguinte diálogo.

Olhem, aqui estão 10 dezenas. Quantos pauzinhos são? (100) Estas dezenas vamos colocar também dentro de uma caixa. Eis aqui a caixa. Nela há lugar para cada dezena. Vamos colocar as 10 dezenas dentro desta caixa! Cabem todas? Por que cabem? (há nela um lugar para cada dezena). Feche a caixa com esta tampa. Quantos pauzinhos estão contidos nesta caixa? A uma caixa de cem chamamos de centena. Repetir. Esta centena vamos colocar a esquerda do lugar onde estavam as dezenas, assim. (BÜCHLER, 1919, p. 188). 


\section{$(\mathrm{cc})$ EY}

Figura 7 - Representação da centena no contador

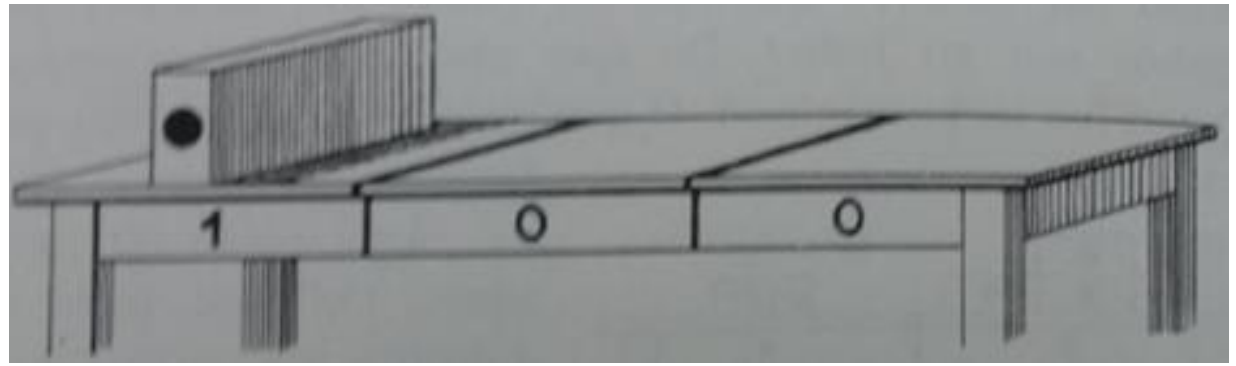

Fonte: Büchler, 1919, p. 188

Após as explicações das dezenas e centenas, explorou o material para realizar as operações de adição e subtração. Por exemplo a adição de 35 e 24: "olhem, estão aqui no contador, 35. Vamos acrescentar 24. Quantas dezenas estão aqui? (3) Quantas unidades? (5) Onde preciso acrescentar as dezenas? (no lugar das dezenas). Quantas dezenas são agora? (5) [...]" (BÜCHLER, 1919, p. 197). De maneira similar, o autor irá trabalhar com as centenas, aumentando gradualmente o número de centenas, até chegar a noção de milhar.

$\mathrm{Na} 1^{\mathrm{a}}$ edição, quinze páginas, ao final do livro, são dedicadas ao professor. Nelas, o autor explica didaticamente como usar o livro. As perguntas que deve formular, os desenhos na lousa, o cálculo mental, os materiais didáticos que usará em sala de aula, atividades de movimentação dos alunos na sala, o uso do contador, etc.

Uma mudança radical ocorreu na $4^{\mathrm{a}}$ edição de 1942, em que a maioria dos textos explicativos sobre o uso do contador desaparecem e ficam apenas as imagens. Assim, as imagens sobre o contador surgem sem um texto explicativo. Por exemplo, na página 43, a primeira vez que contador aparece, ele traz apenas um título: "esta caixa contém dez unidades ou uma dezena" e na mesa aparece a noção de valor posicional, onde o número 1 abaixo da caixa está significando uma dezena e a ausência de material à direita está representada pelo zero, ou como está escrito, "nenhuma unidade ou nada".

Seguindo a mesma orientação, de "limpeza" de textos da $1^{\text {a }}$ edição, as imagens (Figura 8) sugerem uma situação de uso do material sem explicitar como deve ser feito. Apenas uma vez a palavra "contador" é mencionada, em que o autor pede: “Contar doze no contador” (BÜCHLER, 1942, p. 66). 
Figura 8 - Representação do número 10 no contador

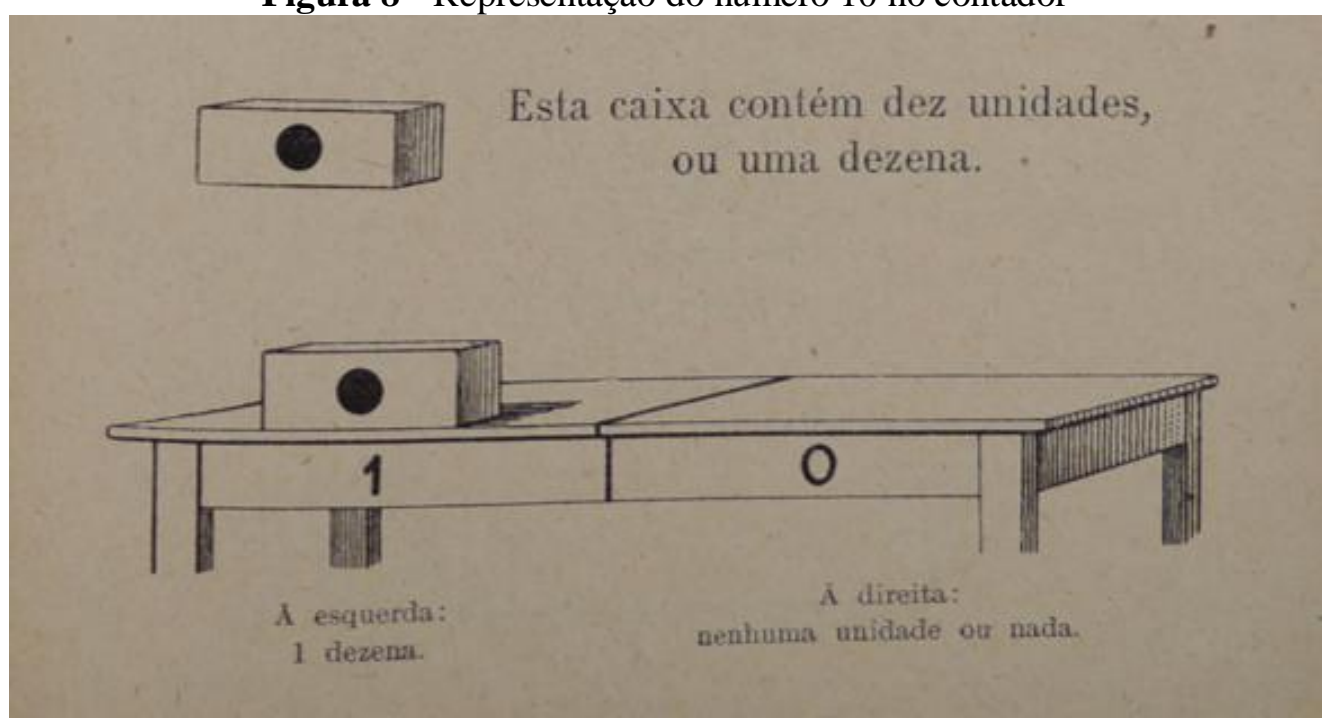

Fonte: Büchler, 1942, 4 ed., p. 43.

O autor traz uma breve explicação sobre as caixas: "A uma caixa de dez chama-se dezena. A uma caixa de cem chama-se centena. O lugar das dezenas é à esquerda do das unidades. O lugar das centenas é à esquerda do das dezenas" (BÜCHLER, 1942, p. 95). Para completar o assunto, aparece mais uma imagem com a noção de milhar, representada com uma caixa de maior tamanho, com o seguinte texto explicativo: "A uma caixa de 10 centenas ou mil chama-se milhar. Os milhares colocam-se na casa à esquerda da centena, i. é, na quarta casa” (BÜCHLER, 1942, p. 116).

A exclusão dos textos que acompanhavam as imagens, conforme mostrado anteriormente, na $1^{\text {a }}$ edição de 1919, sofreu uma ruptura na tentativa do autor comunicar-se com o leitor, pois o contador tornou-se uma ilustração, sem orientação de como usar tal ferramenta, em sala de aula. $\mathrm{O}$ autor na $1^{\mathrm{a}}$ edição procurou tornar seu livro didático não apenas um manual tradicional com exercícios, algoritmos, regras e problemas mas também buscou mostrar o potencial de utilização de um material didático como o contador.

Em 1921, no segundo volume de Arithmetica Elementar de Büchler, o autor refere-se muitas vezes ao "contador Brasil". Suponho que este foi o nome adotado para este material didático e que possivelmente já estava, neste ano, sendo comercializado pela editora. A seguir (Figura 9) imagens do contador contidas no livro. 


\section{$(\mathrm{cc})$ EY}

Figura 9 - Contador Brasil no livro do $2^{\circ}$ ano, 1921.

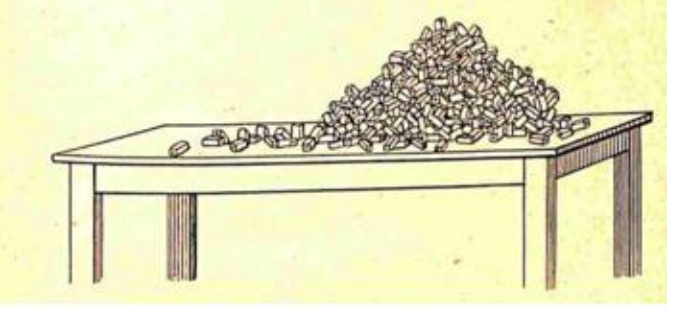

O professor desafia os alunos a descobriren quantos pauzinhos estão na pilha.

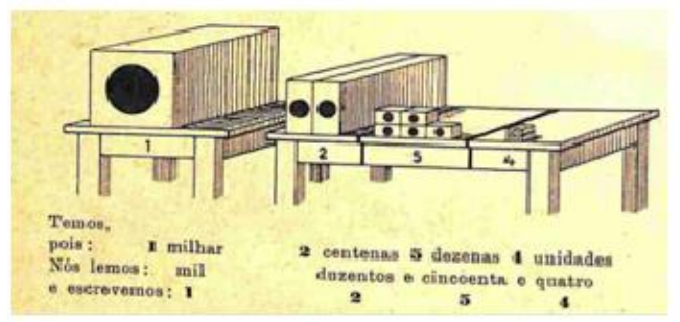

Quando a pilha é arrumada, chega-se a conclusão, a partir da imagem que haviam 1254 pauzinhos.

Fonte: Büchler, 1921, p. 7-8.

Segue-se no livro dezenas de exemplos da utilização do contador para a fixação de conceitos do sistema decimal, assim como realização das quatro operações com o uso do contador Brasil.

\section{O “CONTADOR BRASIL” NO CATÁLOGO DA EDITORA MELHORAMENTOS}

A utilização do contador, conforme proposto no livro de Büchler, pode ter sido a razão que levou a editora Melhoramentos a incluir em seu catálogo um material didático denominado Contador Brasil. Entre os materiais didáticos, que foram comercializados pela Editora Melhoramentos estão entre outros as cartas de Parker e os sólidos geométricos em madeira, etc. No catálogo, consta uma explicação sobre as vantagens técnicas, higiênicas e pedagógicas do contador Brasil. Entre as técnicas estão listadas a facilidade de manuseio, redução de volume, resistência e comodidade. Como vantagem higiênica, Contador Brasil estaria livre de pó (o que faz supor que era confeccionada em madeira), não criaria ferrugem, não cansaria a vista e seria de cores agradáveis. Incluía uma descrição do material, acompanhada da imagem (Figura 10):

Rev. Iberoam. Patrim. Histórico-Educativo, Campinas (SP), v. 05, p. 1-23, e019020, 2019. 
Conteúdo: uma caixa que representa o número 1000 e que contém 10 caixas que representam cada uma o número 100, destas, uma contém 10 volumes que representam cada uma o número 10 e entre estes há duas que contém cada uma 10 unidades. Pode-se, pois, representar qualquer número até 2000 , porque o contingente representa 1000 e as soma do conteúdo é igual a 1000. O aluno pode, pois, contar, somar, diminuir, multiplicar e dividir até o número 2000. Como uma exposição completa demonstra como se forma a dezena, como com as dezenas se forma a centena, e como, com as centenas se obtém o milhar. Explica, sempre exemplificada e praticamente, como os números se compõem de unidades de diferentes ordens. Mostra a razão pela qual todos os números podem ser escritos com dez algarismos (Catálogo, 1937, p. 164)

Figura 10 - Contador no Catálogo da Melhoramentos

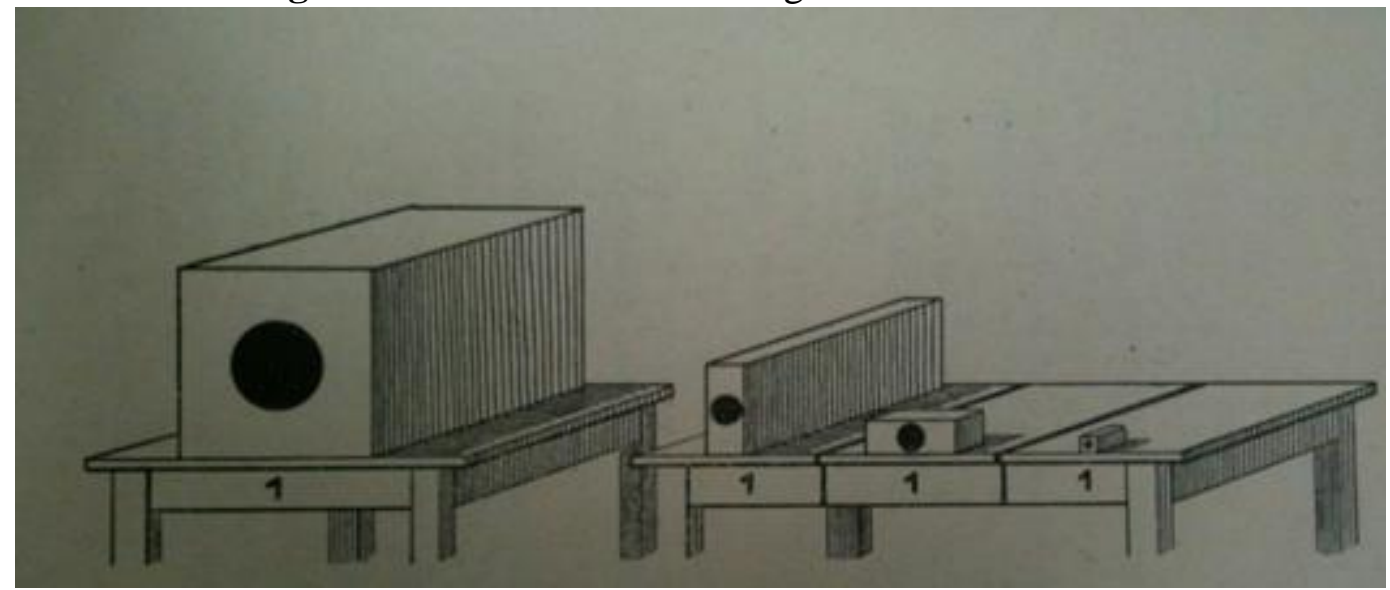

Fonte: Catálogo Editora Melhoramentos, 1937, p. 164.

Comparando a Figura 10 com as imagens das figuras 4-9, nota-se a enorme semelhança entre elas. Isso nos leva a supor que esse material tenha sido produzido após a edição do livro de Büchler e motivado pela importância que o autor atribuiu ao seu uso no ensino do sistema decimal. O grande apelo comercial ao uso do Contador Brasil, no Catálogo, aparece quando afirmam que tal material didático "satisfaz todas as exigências da pedagogia moderna" (CATÁLOGO, 1937, p. 163).

Embora tenha procurado exaustivamente em jornais, revistas, artigos e teses disponibilizadas digitalmente, encontrei apenas uma referência ao uso do "Contador Brasil" na Escola Normal de Juazeiro do Norte (Ceará), em 1934, conforme descrito na pá gina 54, da dissertação de mestrado de Martha Maria Macêdo Bezerra (2013). 


\section{(cc) EY}

\section{CONCLUSÕES}

A produção de ferramentas, também denominadas de materiais didáticos, para uso no ensino da matemática em escolas elementares, aparece na bibliografia internacional desde o século XVIII. Entretanto, intensifica-se no século seguinte, em países europeus e no Brasil. Uma vez que tais produções didáticas sofreram influências transnacionais, sua apropriação em diferentes países também ocasionou adaptações ou inovações. O papel de agentes culturais, dos intercâmbios entre países, quer seja por meio de encontros, exposições, livros de divulgação e viagens de estudos, serviu para disseminar esses materiais didáticos. As vagas pedagógicas como o método ativo e escola nova contribuíram para chamar a atenção sobre o importante papel da visualização no ensino, do uso de materiais didáticos colocados nas mãos do alunos para que este, no ensino fundamental, pudesse fugir à um ensino essencialmente teórico.

Os arithmômetros conhecidos e usados no Brasil, conforme a literatura indica, foram variados e tinham como objetivo auxiliar na compreensão do sistema decimal e do cálculo aritmético.

Georg Büchler inseriu e discutiu em seu livro de 1919 - Aritmetica Elementar - um dispositivo que denominou de contador para auxiliar o ensino do sistema decimal nas salas de aulas de escolas primárias. Ele não se contentou em apenas apresentar tal material didático, mas usou o livro didático para dialogar com o professor, explicando passo a passo como u sá-lo em situação de ensino. É oportuno comentarmos sobre a relevância de analisarmos as diversas edições de obras de um autor, porque se nos limitarmos a análise de apenas uma edição, poderemos perder informações importantes como as modificações significativas que ocorreram entre a $1^{\mathrm{a}}$ e $4^{\mathrm{a}}$ edições da obra de Georg Büchler.

O contador, conforme descrito por Büchler, mostra uma apropriação de versões antigas de um aritmômetro, como aquela da Caixa de calcular de Tillich ou aritmômetro de Martinot, com uma modificação - pauzinhos curtos em lugar de cubos, e caixas substituindo os quadros e grandes cubos.

Livros como os de Georg Büchler, contendo representações de aritmética numa perspectiva inovadora, abrem à discussão para o papel desempenhado pelo livro didático na história do ensino da aritmética no País. Numa época em que as vagas pedagógicas modernas estavam apenas descortinando no País, autores estrangeiros, na escrita de livros didáticos, foram responsáveis

Rev. Iberoam. Patrim. Histórico-Educativo, Campinas (SP), v. 05, p. 1-23, e019020, 2019. 


\section{$(c)$ EY}

juntamente com autores brasileiros por sua disseminação e serviram como uma ponte entre saberes escolares produzidos pelos especialistas e os professores, sujeitos que interpretaram e usaram tais manuais.

Este autor contou com o suporte da editora Melhoramentos que comercializou o contador e que lhe deu um nome - Contador Brasil. A presente investigação não conseguiu esclarecer se houve uso efetivo e circulação desse material nas escolas primárias. Entretanto, mostrou uma apropriação de aparatos germânicos em terras brasileiras.

\section{REFERÊNCIAS}

AVISO. Gazeta de Notícias (RJ), 22 dez. 1883, p. 2.

BENITO, Agustin Escolano. A escola como cultura: experiência, memória e arqueologia. Campinas: Alinea, 2017.

BEZERRA, Martha M. M. De aluno a professor a formação docente de egressos da Escola Normal Rural de Juazeiro do Norte Ceará. 2013. Sem numeração. Dissertação (Mestrado em Educação) - Universidade Estadual do Ceará.

BÜCHLER, Georg August. Arithmetica Elementar. Livro I: para o ensino primario, de acordo com os programmas officiaes. São Paulo: Weiszflog, 1919.

BÜCHLER, Georg August. Arithmetica Elementar. Livro II. São Paulo: Companhia Editora Melhoramentos, 1921.

BÜCHLER, Georg August. Aritmética Elementar. Livro I: para o ensino primário, de acordo com os programas oficiais e adotada em todos os estados. São Paulo: Companhia Editora Melhoramentos, 1942.

BUISSON, F. Dictionnaire de Pédagogie et d'Instruction Primaire. V. 2. Paris: Hachette, 1887.

CASTRO, Isabel. Revista Eschola Publica (SP), Anno I, n. 1, p. 41-42, 1896.

CATÁLOGO de livros e material didactico. São Paulo: Cia Melhoramentos, 1937.

DANTAS, Manoel Correa. Material pedagógico. O Paiz (RJ), 9 de out. 1929, p. 2.

DECRETO. 14 de março de 1890. Disponível em: http://repositorio.ufsc.br/handle/123456789/103579. Acesso em: 14 fev. 2019. 


\section{(c) $) \mathrm{EY}$}

DITTRICHT, Klaus. As exposições universais como mídias para a ação transnacional de saberes sobre o ensino primário na segunda metade do século 19. Hist. Educ. (Online), Porto Alegre, v. 17, n. 41, p. 213-234, set./dez. 2013.

ESPAGNE, Michel. Les transferts culturels franco-allemands. Paris: Presses Universitaires de France, 1999.

FONTAINE, Alexandre. Pedagogia como transferência cultural no espaço franco-suíço: mediadores e reinterpretações de conhecimento (1850-1900). História da Educação, Porto Alegre, v. 18, n. 42, p. 187-207, 2014.

EXPOSIÇÃO Pedagógica. Gazeta de Notícias (RJ), 24 jun. 1883, p. 3.

EXPOSIÇÃO Pedagógica. A Folha Nova, 10 nov. 1883, p. 2.

LEXIS, W. Das Unterrischtswesen im Deutschen Reich. III Band (Das Volksschulwesen und das Lehrerbildungswesen). Berlin: Asher \&Co, 1904.

PAIS, Luiz Carlos. História dos Aritmômetros Escolares no Ensino Primário da Matemática no Brasil (1883 - 1927). EM TEIA: Revista de Educação Matemática e Tecnológica Iberoamericana, v. 5, n. 2, p. 1, 2014. Disponível em: https://periodicos.ufpe.br/revistas/emteia/article/view/2201/1772. Acesso em: 24 jul. 2017.

PLANE, Sylvie; SCHNEUWLY, Bernard (Org.) REPÈRES: recherches en didactique du français langue maternelle: Les outil d`enseignement du français. N. 22. França, Paris: Institut National de Recherche Pédagogique, 2000.

REGNER, Jean Claude. Le Boulier-Numérateur de Marie Pape-Carpantier. Bulletin de l'APMEP, Association des Professeurs de Mathématiques de l'Enseignement Public, p. 457-471, 2003.

REIS, Luiz A. O Ensino Público Primário em Portugal, Espanha, França e Bélgica. Rio de Janeiro: Imprensa Nacional, 1892.

RELATORIO dos Trabalhos do Conselho Interino de Governo (BA), 1882, p. 76-77. Disponível em:

http://memoria.bn.br/DocReader/DocReader.aspx?bib=130605\&pesq=Carpentier\&pasta=ano\%2 0188. Acesso em: 12 maio 2018.

SANTOS, Theobaldo Miranda. Noções de didática geral. São Paulo: Companhia Editora Nacional, 1955.

SANTOS, Theobaldo Miranda. Noções de didática especial. São Paulo: Companhia Editora Nacional, 1960.

SÃO PAULO. Revista A Eschola Publica. anno I. no. 1. São Paulo: Typographia da Industrial

Rev. Iberoam. Patrim. Histórico-Educativo, Campinas (SP), v. 05, p. 1-23, e019020, 2019. 


\section{$(\mathrm{cc}) \mathrm{BY}$}

de São Paulo, 1896. Disponível em: https://repositorio.ufsc.br/xmlui/handle/123456789/126749. Acesso em: 13 jul. 2018.

SILVA, Circe Mary Silva. Representações de Aritmética no livro de Georg Büchler.

HISTEMAT, ano 2, n. 1, p. 96-116, 2016.

TEIXEIRA, Giselle Baptista. Os "Princípios Elementares da Arithmetica" nas escolas da corte imperial. Cadernos de História da Educação, v. 13, n. 2, jul./dez., p. 603-624, 2014.

UNGER, Friedrich. Die Methodik der praktischen Arithmetik in historischer entwicklung vom ausgange des mittelaters bis auf die gegenwart. Leipzig: Teubner, 1888.

Recebido em: 20 de maio de 2019

Aceito em: 26 de outubro de 2019 